\section{A biocompatible and bioactive replacement for dentine: is this a reality? The properties and uses of a novel calcium-based cement}

\author{
I. K. Bachoo, ${ }^{1}$ D. Seymour ${ }^{2}$ and P. Brunton ${ }^{3}$
}

IN BRIEF
- Highlights the shortcomings of current
restorative materials and the subsequent
drive to develop new dental materials
which induce regeneration of lost tissue.
- Presents evidence-based research on
the physical, mechanical, chemical
and biological properties of a 'new
regenerative' calcium-based material.
Discusses the clinical indications of a
novel dental material within general
practice.

As part of the continuing evolution towards conservative dentistry there has been a drive to push further and investigate the possibility of inducing the repair and regeneration of lost dental hard tissue. Until recently, the prospect of repair and regeneration had been confined to laboratory studies and hypothesised scientific models. In 2009, a new product was launched claiming to be a revolutionary material capable of offering a bioactive and biocompatible replacement for dentine. The calcium-based cement is reported to preserve pulp vitality, promote pulp healing and provide a natural substitute for dentine through bioactive stimulation of the dentino-pulpal complex. Its clinical indications are extensive, described as a restorative material suitable for use wherever dentine replacement is required. In this article the physical, mechanical, chemical and biological properties of this novel material are presented, together with the results of experimental laboratory-based investigations and on-going clinical in vivo investigations.

\section{INTRODUCTION}

Conventional restorative materials have long been associated with a variety of limitations. For example amalgam is associated with more destructive cavity preparations, is deemed inappropriate for visible restorations and is implicated in ecological pollution. ${ }^{1}$ While the evolution of resin-based restorative materials has largely addressed these concerns, they have brought their own set of difficulties, including the release of pulp-damaging toxic monomers, polymerisation shrinkage and microleakage. ${ }^{1,2}$ Consequently, there has thus been a shift of thinking in more recent years towards developing materials which do more than simply aim to replace lost tooth tissue but rather seek to induce its repair and regeneration.

In the 1990s this led to the development of mineral trioxide aggregate (MTA), a biocompatible material composed principally of tricalcium and dicalcium silicate. ${ }^{2-4}$ In one study, this material has been shown to

\footnotetext{
Senior House Officer in Restorative Dentistry, ${ }^{2}$ Speciality Registrar in Restorative Dentistry, ${ }^{3}$ Professor and Honorary Consultant in Restorative Dentistry, Leeds Dental Institute

${ }^{*}$ Correspondence to: Ishpinder Kaur Bachoo Email: ishpinder.bachoo@gmail.com
}

\section{Online article number E5}

Refereed Paper - accepted 6 July 2012

DOI: $10.1038 /$ sj.bdj.2013.57

${ }^{\oplus}$ British Dental Journal 2013; 214: E5

\begin{tabular}{|c|c|}
\hline Powder (1 g) & Liquid (200 ml) \\
\hline Tricalcium silicate $\left(3 \mathrm{CaOSiO}_{2}\right)$ & Calcium chloride $\left(\mathrm{CaCl}_{2} \cdot 2 \mathrm{H}_{2} \mathrm{O}\right)$ \\
\hline Calcium carbonate $\left(\mathrm{CaCO}_{3}\right)$ & Water reducing agent \\
\hline Zirconium dioxide $\left(\mathrm{ZrO}_{2}\right)$ & Water \\
\hline
\end{tabular}

\begin{tabular}{|c|c|}
\hline Component & Function \\
\hline Tricalcium silicate $\left(3 \mathrm{CaOSiO}_{2}\right)$ & Main component of the powder. It regulates the setting reaction \\
\hline Calcium carbonate $\left(\mathrm{CaCO}_{3}\right)$ & Acts similar to a filler \\
\hline Zirconium dioxide $\left(\mathrm{ZrO}_{2}\right)$ & Provides radio-opacity to the cement \\
\hline Calcium chloride $\left(\mathrm{CaCl}_{2} \cdot 2 \mathrm{H}_{2} \mathrm{O}\right)$ & Acts as an accelerator \\
\hline Water reducing agent & $\begin{array}{l}\text { Reduces the viscosity of the cement to achieve workability, while } \\
\text { reducing the water content }\end{array}$ \\
\hline
\end{tabular}

stimulate reparative dentine and complete bridge formation in vivo after with no signs of inflammation following pulp capping in $83 \%$ of teeth tested. ${ }^{5}$ However, it's extended setting time of 2 hours 45 minutes $^{3}$ and reduced mechanical properties mean that MTA cannot be considered compatible for use as a dental restorative material. ${ }^{2}$ Building on the therapeutic properties of MTA, a superior clinical medicament would be a desirable addition for clinicians. It is suggested that a recently launched material, Biodentine $^{\mathrm{TM}}$ (Biodentine, Septodont, Saint
Maur Des Fossés, France), may well be the first in a new class of such dental materials. ${ }^{6,7}$ The aim of this article is to describe this novel material in greater detail and in an associated practice paper, illustrate its use in clinical case reports.

\section{COMPOSITION}

Biodentine $^{\mathrm{TM}}$ is an inorganic, non-metallic compound presented in a capsulated powder and liquid form. The powder phase consists of tricalcium silicate, calcium carbonate and zirconium dioxide and 
the liquid phase combines calcium chloride, water and a water reducing agent (Table 1). ${ }^{8}$ The properties of the materials' constituents are summarised in Table 2.

\section{SETTING REACTION}

Upon mixing of the powder phase with the liquid phase the following sequence of events occur:

1. Tricalcium silicate mixes with

the water component and leads

to the formation of a hydrated

calcium silicate gel (C-S-H) structure and calcium hydroxide. The gel layers form following dissolution of the tricalcium silicate grains causing precipitation of a calcium silicate gel structure ${ }^{9}$

2. Growth of the gel structure develops through nucleation and growth on the tricalcium silicate surface and gradually fills the spaces in between the tricalcium silicate grains ${ }^{10}$

3. Crystallisation of the C-S-H gel structure occurs through continuous hydration, resulting in the formation of $\mathrm{CaCO}_{3}$ crystals in between the unreacted grains. The crystals of $\mathrm{CaCO}_{3}$ slowly fill in the porosities between the unreacted grains of cement over a period of approximately two weeks until finally reaching a maximum. ${ }^{9}$ This process of crystallisation makes the structure relatively impermeable to water and slows down the effects of further reactions. ${ }^{9}$

The complete hydration reaction is summarised by the following formula: ${ }^{9}$

$2\left(3 \mathrm{CaO} . \mathrm{SiO}_{2}\right)+6 \mathrm{H}_{2} \mathrm{O}---->$ $3 \mathrm{CaO} \cdot 2 \mathrm{SiO}_{2} \cdot 3 \mathrm{H}_{2} \mathrm{O}+3 \mathrm{Ca}(\mathrm{OH})_{2}$

\section{MOLECULAR STRUCTURE OF SET MATERIAL}

The final structure of the set material is composed of a hydrated calcium silicate gel matrix with crystals of $\mathrm{CaCO}_{3}$ interposed between unreacted grains of cement (Fig. 1).

\section{SETTING TIME}

The initial setting reaction takes approximately 12 minutes, however, ${ }^{6}$ through impedance spectroscopy tests it has been shown that at least two weeks are necessary for the material to finally set. ${ }^{9}$ As mentioned

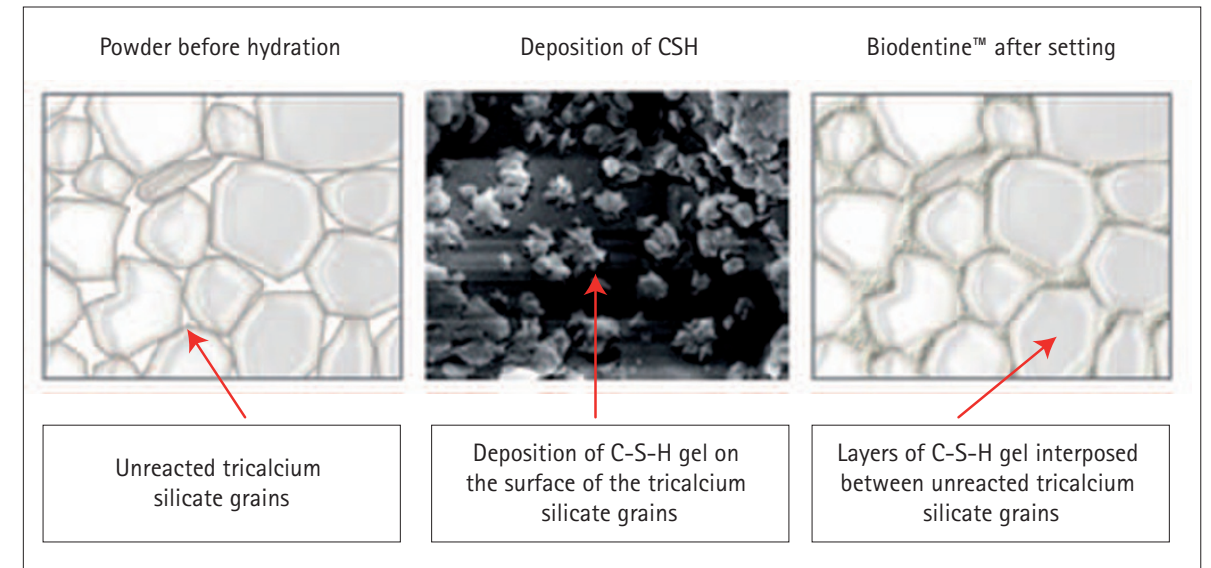

Fig. 1 Pictorial depiction of setting reaction. Courtesy of Biodentine ${ }^{\mathrm{TM}}$ Research and Development Department, Septodont internal data $2009^{6}$

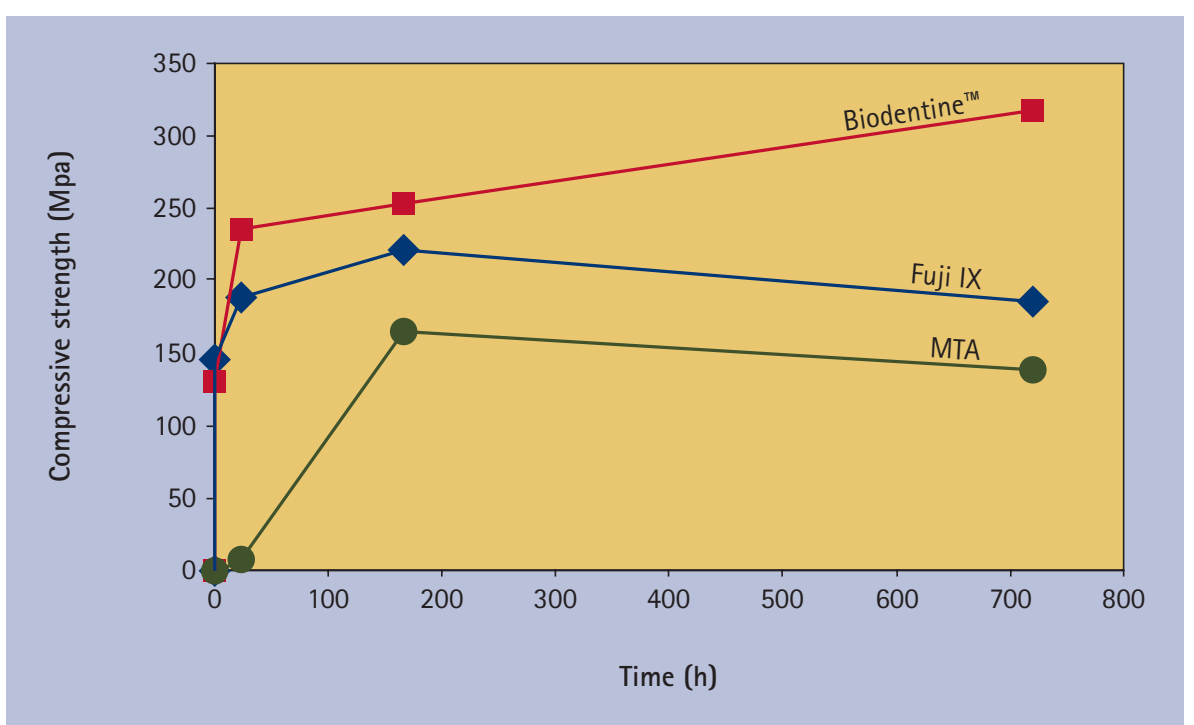

Fig. 2 Comparative evolution of compressive strength after setting. Courtesy of Biodentine ${ }^{\mathrm{Tm}}$. Research and development file, the manufacturer's internal data $2009^{6}$

earlier, it is during this period that the $\mathrm{CaCO}_{3}$ crystals are still being formed. This setting time represents an improvement compared to other calcium silicate-based dental materials such as MTA, which take more than two hours to reach an initial set. ${ }^{3}$ This reduction in setting time is reported to have been achieved by: ${ }^{6}$

- Higher specific surface size of particles

- Addition of calcium chloride accelerator to liquid phase

- Decrease in the liquid content.

\section{MECHANICAL AND PHYSICAL PROPERTIES}

The mechanical and physical properties of a dental material are key to its' suitability for clinical use. These attributes will often dictate the material's clinical indications.

\section{Compressive strength}

Cylinders of Biodentine ${ }^{\mathrm{TM}}$, made from Teflon moulds, were created and stored wet in distilled water at $37{ }^{\circ} \mathrm{C}$ to simulate clinical conditions. The cylinder was loaded into a universal testing machine and a constant cross-head speed of $0.5 \mathrm{~mm} /$ minute was applied in order to assess the material's compressive strength. The computer system records the load and amount of compression of the material. MTA and 'FUGI IX' were tested for comparison and each material was tested at 1 hour, 24 hours, 7 days and 28 days. The results obtained (Fig. 2) illustrate Biodentine ${ }^{\mathrm{TM}}$ displays a sharp increase in compressive strength in the first hour, reaching $100 \mathrm{MPa}$, and rising to $200 \mathrm{MPa}$ at 24 hours. ${ }^{6}$ Its final compressive strength is approximately $300 \mathrm{MPa},{ }^{6}$ which is in the range of natural dentine at $297 \mathrm{MPa} .{ }^{10}$ The final compressive strength of 'FUGI IX' was observed to be much lower at $185 \mathrm{MPa}$, and MTA only reached a registerable MPa at 24 hours. ${ }^{6}$ The manufacturer reports 
this highlights a distinct advantage over Biodentine's ${ }^{\mathrm{TM}}$ closest alternatives (Fig. 2).

\section{Vickers microhardness and flexural strength}

Vickers hardness testing, which evaluates resistance to plastic deformation of the surface after indentation, has indicated that the novel material would fare better against surface wear in relation to resinmodified glass-ionomer cement (RMGIC) yet not as well in comparison to light cure composite. ${ }^{9}$ The flexural strength of the material, measured through a three point bending test, however, is poorer than that of both RMGIC and light-cure composite and indicates the risk of cohesive fracture would be higher with this material. ${ }^{9}$ This is of clinical significance in Class I, II and IV cavities. ${ }^{9}$

\section{Micromechanical bond}

It is thought that the interfacial layer observed between the material and dentine is similar to the hard tissue layer formed with MTA, which is considered to be a dentinal bridge or precipitation of hydroxyapatite. ${ }^{11}$ It is proposed this bridge is formed via crystal growth within the dentine tubules, leading to a micromechanical anchor (Fig. 3). ${ }^{9}$ The manufacturer claims as the crystallisation process continues with time, the formation of the micromechanical bond also thus improves. ${ }^{6}$ Possible ion exchanges between the cement and dentinal tissues have been suggested as an alternative hypothesis, or thirdly that, both processes may combine to achieve the adhesive properties observed.

\section{Radiopacity}

The new material uses zirconium dioxide to impart radio-opacity, which is a useful feature for identification of recurrent caries and for the assessment of endodontic repairs. In an associated Practice paper by the authors of this article, this feature will be further discussed.

\section{CHEMICAL PROPERTIES}

The quality and durability of the material/tooth interface is a key factor to the survival and longevity of a restorative material within clinical conditions. This feature has been tested via acid erosion, aging in artificial saliva and resistance to microleakage tests.

\section{Chemical behaviour in acidic conditions}

Resistance to acid attack is an important feature for all restorative materials exposed to the oral environment. The acid erosion test has been evaluated through daily submersion of samples of this novel material in lactic acid $(0.02 \mathrm{M})$ and sodium lactate $(0.1 \mathrm{M})$ aqueous solution giving a $\mathrm{pH}$ of $2.74 .{ }^{12}$ The height loss of the material sample was measured for a week and was reported to reveal a slower rate of erosion compared to 'FUGI II' but a similar rate compared to Ketac Fil GIC. ${ }^{12}$

\section{Chemical behaviour in a simulated oral environment}

Samples of the new material have been investigated for aging by immersion in Meyer-modified Fusayama artificial saliva (pH 5.3). ${ }^{12}$ Examination of the samples with scanning electron microscopy and $\mathrm{X}$-ray diffraction analysis revealed deposition of a white material on the outer surface, with a needle-like apatitic appearance, composed of calcium phosphate. It is suggested this crystal deposition on the surface of the new material may lead to an increase in the marginal sealing of the material. ${ }^{12}$ This type of crystal deposition is already well known for MTA systems. ${ }^{6}$

\section{Resistance to microleakage}

\section{Enamel/dentine interface}

Microleakage has been tested via dye penetration studies using silver nitrate..$^{9,13}$ These studies have shown that microleakage at the enamel/dentine interface is low with dye penetration of $17.65 \%$ and $10.46 \%$ associated with the interface with enamel and dentine respectively. The Tran et al. study further reported that cavity conditioning of the enamel/dentine surface with polyacrylic acid before application of the material did not yield improved resistance against microleakage. ${ }^{13}$ The material's microleakage capabilities have further been tested in comparison to 'FUGI II LC. ${ }^{6}$ Mesio-occlusal and disto-occlusal cavities were prepared in extracted molars and randomly treated with Biodentine ${ }^{\mathrm{TM}}$ or 'FUGI II LC'. Both groups were then finally restored with a composite restoration. At the enamel/dentine interface the new material was reported to exhibit better resistance to leakage compared to 'FUGI II'

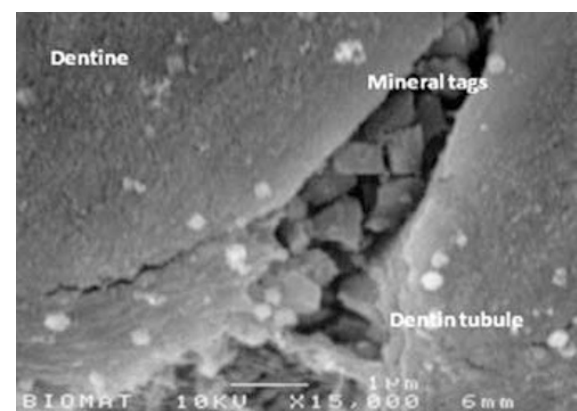

Fig. 3 Electron Microscopy view of micromechanical anchor of material into dentine tubule. Courtesy of Professor Colon, Dr Pradelle. Biodentine ${ }^{T M}$ Research and development file, the manufacturer's internal data $2009^{6}$

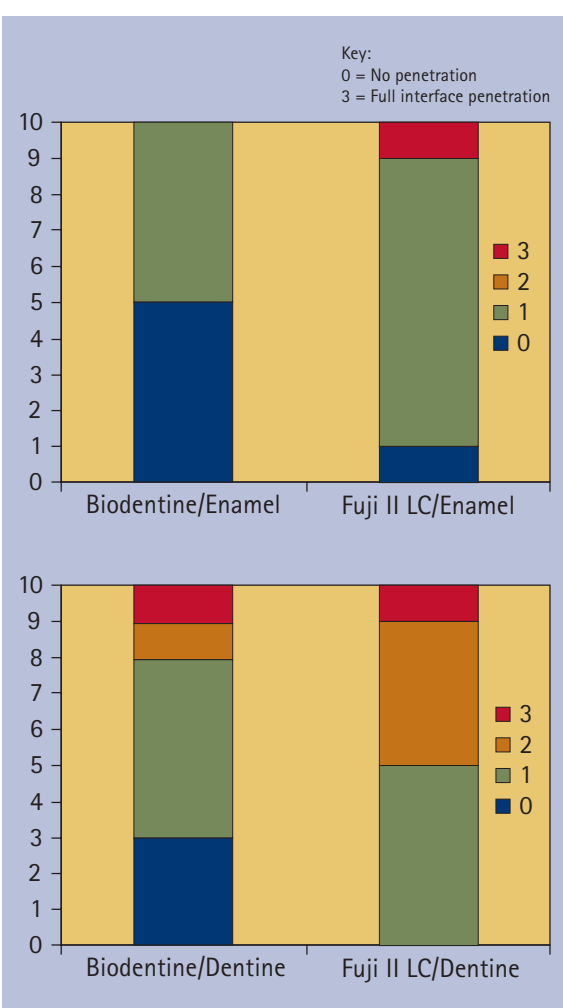

Fig. 4 Microleakage scores of Biodentine $^{\mathrm{TM}} /$ 'FUGI II LC' at enamel/dentine interface. Courtesy of Professor Déjou and Dr Raskin. Biodentine ${ }^{T M}$ Research and development file, the manufacturer's internal data $2009^{6}$

LC (Fig. 4).The authors report this study highlights the exceptional sealing capabilities of the material. ${ }^{6}$ In a similar study by Koubi et al. the marginal integrity of Biodentine and resin-modified glass ionomers in class II open sandwich restorations was compared. ${ }^{14}$ This study used glucose diffusion as opposed to silver nitrate to evaluate microleakage. The results showed no statistical difference in microleakage observed at the dentine-material interface when comparing Biodentine ${ }^{\mathrm{TM}}$ and resin-modified glass ionomer. The authors 
indicate the good marginal integrity observed with Biodentine ${ }^{\mathrm{TM}}$ is likely due to the outstanding ability of the calcium silicate materials to form hydroxyapatite crystals at the surface.

Since it appears Biodentine ${ }^{\mathrm{TM}}$ requires no cavity conditioning or photo activation, as with resin modified glass-ionomer cement, it offers clear advantages in that it can be applied in bulk with clinical efficiency and with no compromise to the quality of the marginal seal.

\section{Composite interface}

The microleakage capabilities of the new calcium based cement at the interface with composite resins has been tested and the results reveal surface preparation of the material with phosphoric acid for $15 \mathrm{sec}-$ onds followed by application of a silane coupling agent results in an excellent seal against microleakage. ${ }^{15}$ Furthermore, this preparation produces the highest shear bond strengths compared to other surface preparations. An on-going in vivo investigation by Koubi et al. ${ }^{8}$ has presented initial results from a clinical study in which the novel material has been used in conjunction with composite filling material. The results have shown that where the material was first applied as a bulk replacement material, and then cut-back for use as either a dentine substitute or liner and combined with Z100 composite, that these restorations are performing well on review. Importantly, there has been no bacterial infiltration or secondary caries observed at the Biodentine $\mathrm{T}^{\mathrm{TM}} /$ composite interface.

\section{BIOLOGICAL PROPERTIES}

\section{Bioactivity}

The calcium-based cement is reported to display novel bioactive properties and can achieve biomimetic mineralisation within the depths of a carious cavity. This attribute of the material comes following several laboratory-based experimental investigations which have shown promising evidence for the material's reported bioactivity. In the first experiment bioactivity was tested through incubation of pulp cells with a media conditioned with extracts of the novel material. ${ }^{6}$ The results showed these cells expressed a high level of odontoblastic cell markers which induced the synthesis of mineralisation
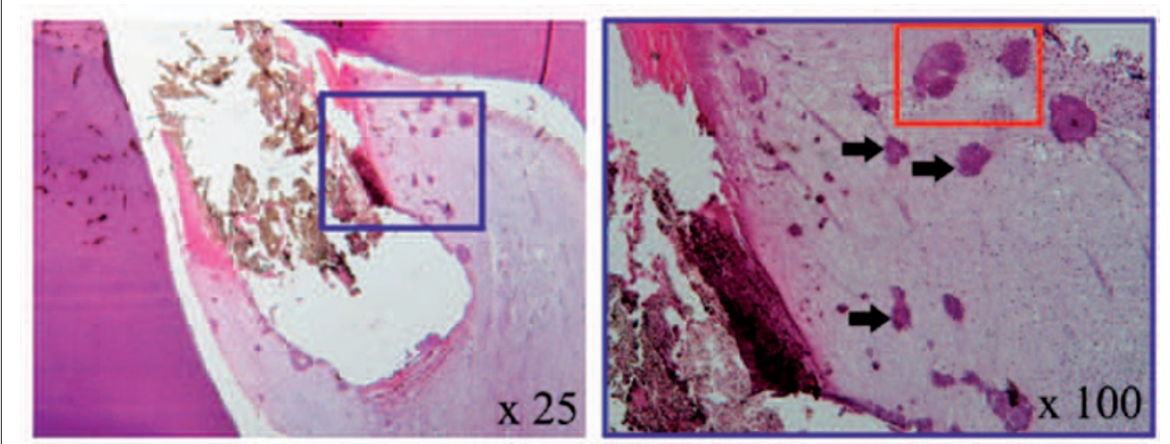

Fig. 5 Histological samples following pulp capping after 28 days. Courtesy of Professor About, Biodentine $^{\text {TM }}$ Research and development file, the manufacturer's internal data $2009^{9}$

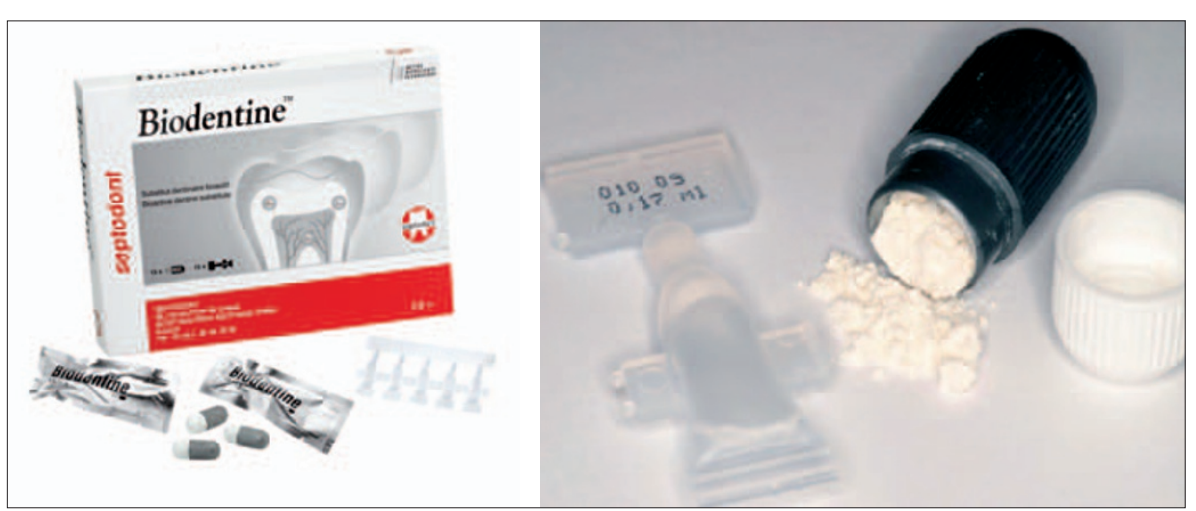

Fig. 6 Presentation of Biodentine ${ }^{T M}$. Courtesy of Biodentine ${ }^{T M}$ Research and development file, the manufacturer's internal data $2009^{9}$

nodules that have the molecular characteristics of dentine. ${ }^{6,17}$ Boukpessi et al. ${ }^{17}$ have carried out in vivo experiments on non-exposed cavities made in rat molars. One group had the cavities restored with GIC, one group was left with unrestored cavities and the test group received Biodentine $^{\mathrm{TM}}$. Histological analysis at day eight of cavities treated with the new material showed a $20-40 \mu \mathrm{m}$ thick layer of reactionary dentine which gradually increased to $140-280 \mu \mathrm{m}$ at day 30 . In comparison the other two groups displayed a dentine layer only 10-20 $\mu \mathrm{m}$ for the same period of time. I. About ${ }^{6}$ has investigated the material's bioactive properties through performing direct pulp capping on extracted human teeth. Exposed pulp cavities were restored with the new material and cultured for 24 hours, 14 days and 28 days. At the end of the culture period following demineralisation, histological samples were produced. The results showed good preservation of pulpal tissue and near the capped area formation of a reparatory dentine-type material was observed (Fig. 5). The author reports this corresponds to the first signs of dentine bridge formation. In a related study (Laurent et al.) ${ }^{18}$ the ability of Biodentine ${ }^{\mathrm{TM}}$ to induce reparative dentine synthesis and to modulate TGF- $\beta 1$ secretion has been investigated. Through direct application of Biodentine ${ }^{\mathrm{TM}}$ to an ex vivo dental pulp in an entire human tooth culture, mineralised foci with the morphological appearance of osteodentine was observed. The authors report this corresponds to an early step of reparative dentine synthesis seen in vivo. The role of growth factors, and in particular TGF- $\beta 1$, is thought to be crucial to wound healing and dentinal-pulp regeneration. TGF- $\beta 1$ secretion by pulp cells in response to contact with Biodentine ${ }^{\mathrm{TM}}$ was secondly investigated. A statistically significant increase in TGF- $\beta 1$ secretion was seen after incubating cells with Biodentine ${ }^{\mathrm{TM}}$. The same was true when testing with MTA. The authors hypothesise therefore that the stimulation of the observed reparatory dentine could be the result of the new material's ability to modulate TGF- $\beta 1$ secretion. The clinical relevance of these findings are of importance in the pursuit of maintaining pulpal vitality following carious, traumatic or iatrogenic injuries.

Shayegan ${ }^{6}$ reports the material exhibits calcification following pulpotomies 

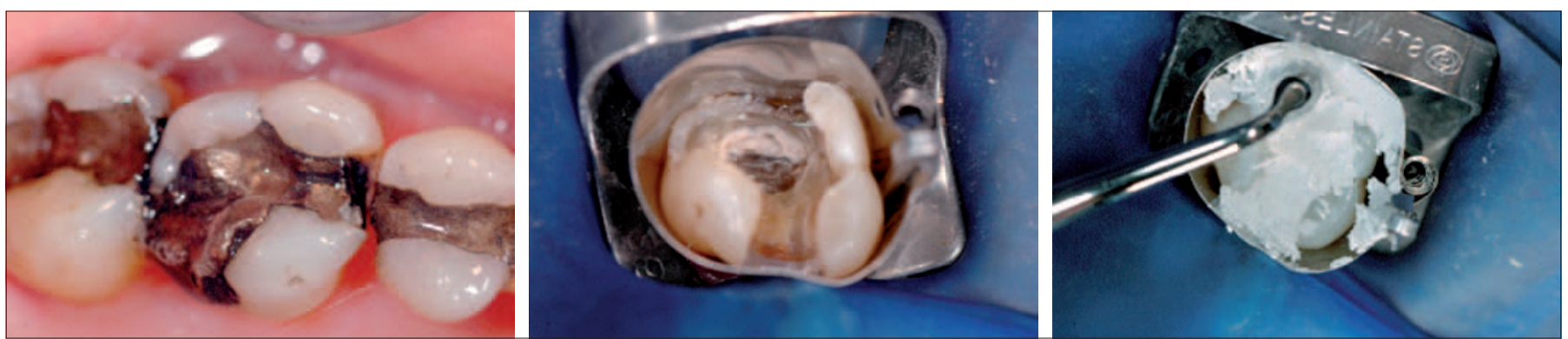

Fig. 7 Biodentine $^{\mathrm{TM}}$ being used as a bulk dentine substitute. Courtesy of Professor Koubi, Marseille (2009)

performed on 15 in vivo pig teeth. The material's efficacy was compared to Formocresol and MTA. Following extraction, histological analysis was performed at one week, one month and three months. The author reports the results showed Biodentine ${ }^{\mathrm{TM}}$ induced beneficial calcification, comparable to MTA. In contrast, Formocresol initiated necrosis and inflammation. It is claimed that these studies have shown the ability of the material to promote mineralisation, generate reactionary dentine and induce the formation of a dense mineralised dentine-type bridge, therefore substantiating the claim that the cement is highly bioactive. ${ }^{6}$

Finally, in a recent study, the uptake of calcium and silicon into root canal dentine has been investigated by Han and Okiji. ${ }^{19}$ Root canals of bovine incisor root segments were instrumented and filled with either Biodentine ${ }^{\mathrm{TM}}$ or MTA. The uptake of Ca and Si by the adjacent root dentine in the presence of phosphate buffered saline was then observed using a wavelength-dispersive X-ray spectroscopy electron probe micro-analyser. Results showed at the material-dentine interface both materials formed a tag-like crystalline structure within the dentinal tubules. Furthermore, a $\mathrm{Ca}$ and $\mathrm{Si}$ rich interfacial layer was detected, which was significantly larger in Biodentine ${ }^{\mathrm{TM}}$ than MTA. It is suggested uptake of $\mathrm{Ca}$ and $\mathrm{Si}$ probably causes chemical and structural modification to the surrounding dentine, which may result in higher acid resistance and physical strength. The authors report this indicates the bioactivity of the new material and postulate its biomineralisation properties are superior to that of MTA.

\section{Biocompatibility}

Biocompatibility has been investigated through a series of biological tests. ${ }^{7}$
Ames' tests performed to evaluate any evidence of mutagenicity have failed to detect significant reverse mutations. ${ }^{7,20}$ The micronucleus test was performed on human lymphocytes in order to detect any structural chromosomal alterations in these host cells and also revealed no chromosomal damage. ${ }^{7}$ A comet assay was performed on human pulp fibroblasts of odontoblastic cells, and did not show significant DNA damage in human pulp fibroblasts or adverse effects on their function. ${ }^{7}$ Finally, Cytotoxic studies revealed no ill effect on the functions of human pulp fibroblasts. ${ }^{7,20}$

These biological tests have shown that this new material is biocompatible and comparable to MTA, by its absence of cytotoxicity, genotoxicity mutagenicity. This is of particular clinical significance as it indicates that the material can be placed directly onto teeth where the odontoblastic layer may be partially destroyed, without any adverse effects on the pulp healing activity of pulp fibroblasts (protein expression and mineralisation). Indeed, with its reported bioactive properties the presence of Biodentine ${ }^{\mathrm{TM}}$ could actually promote pulpal healing and repair.

\section{PRESENTATION}

The material is presented in the form of a capsulated powder and a liquid twist cap bottle (Fig. 6).

\section{HANDLING AND MANIPULATION}

The material is prepared by mixing with an amalgamator. However, the initial preparation involves tapping and opening the capsule containing the powder, followed by the addition of five drops of liquid from the single dose container to the capsule. This is then closed and placed in an amalgamator for 30 seconds. It can then be handled with an amalgam carrier, spatula or root canal Messing gun. ${ }^{21}$ The total handling time is 12 minutes, allowing 6 minutes for mixing and placement and a further 6 minutes for setting. ${ }^{9}$

\section{INDICATIONS}

Recommended indications include: ${ }^{21}$

- Temporary enamel replacement

- Permanent dentine replacement

- Restoration of deep and/or large coronal carious lesions (sandwich technique)

- Restoration of deep cervical and/or radicular lesions

- Pulp capping

- Pulpotomy

- Repair of root perforation

- Repair of furcation perforation

- Repair of perforating internal resorptions

- Repair of external resorptions

- Apexification

- Root end filling in endodontic retrograde surgery.

\section{LIMITS OF USE}

The limits of use include restoration of a large loss of tooth substance exposed to high stress, aesthetic restoration of anterior teeth and treatment of teeth with irreversible pulpitis.

\section{ONGOING CLINICAL STUDIES}

So far most of the experimental in vitro studies and clinical in vivo studies have focused on use of the new material as a bulk dentine restorative material or indirect pulp capping agent. The on-going in vivo clinical study from Koubi et al. ${ }^{8}$ is principally concerned with its longevity following restoration of Class I and Class II cavities. In this study 116 cavities were restored in bulk with Biodentine ${ }^{\mathrm{TM}}$ without surface preparation of the cavity. For some cavities (20) pulpal exposure occurred and for these teeth the new material served as a 
direct pulp cap as well as a bulk restorative material (Figs 7 and 8).

The interim three-year follow-up report of this study has shown a mean survival of 12 months, with a minimum longevity of 6 months and a maximum of 35 months. ${ }^{8}$ The only reason cited for the replacement of the Biodentine ${ }^{\mathrm{TM}}$ in any of the treated teeth has been due to occlusal wear and degradation of the interproximal contact. In these cases the Biodentine ${ }^{\mathrm{TM}}$ was kept as a dentine substitue and resurfaced with composite. Of all the 116 teeth included in the study none displayed evidence of secondary caries, microleakage, or caused the patient any symptoms. Conclusions drawn from the study so far suggest that this new material can be used effectively as a pulp capping agent and as a bulk temporary restorative material at the same time. ${ }^{8}$ The authors of the study report the material displays all the necessary qualities for a dentine substitute ie biocompatibility and longevity. Finally the study comments the material is user-friendly with easy handling and good marginal adaptation properties. ${ }^{6}$

Goldberg et al. ${ }^{1}$ mentions that there is another second on-going clinical study being carried out by a group in Paris Diderot, where the material is being tested as a medium-term temporary filling material or as a permanent dentine replacement under resin-containing or inlay/ onlay restorations. No results have yet been published from this study at the time of writing.

The endodontic indications of the new material are similar to MTA, but are reported to offer several advantages including: ${ }^{6}$

- Better consistency suited to clinical use compared to MTA

- Improved handling as a result of the presentation of material

- Quicker setting time means it eliminates two-step obturation as with MTA and reduced risk of bacterial contamination.

The tolerance and efficacy of Biodentine $^{\mathrm{TM}}$ in six endodontic procedures is therefore being studied by Machtou. ${ }^{6}$ The procedures include:

- Direct pulp capping following carious pulp exposure

- Direct pulp capping following dental
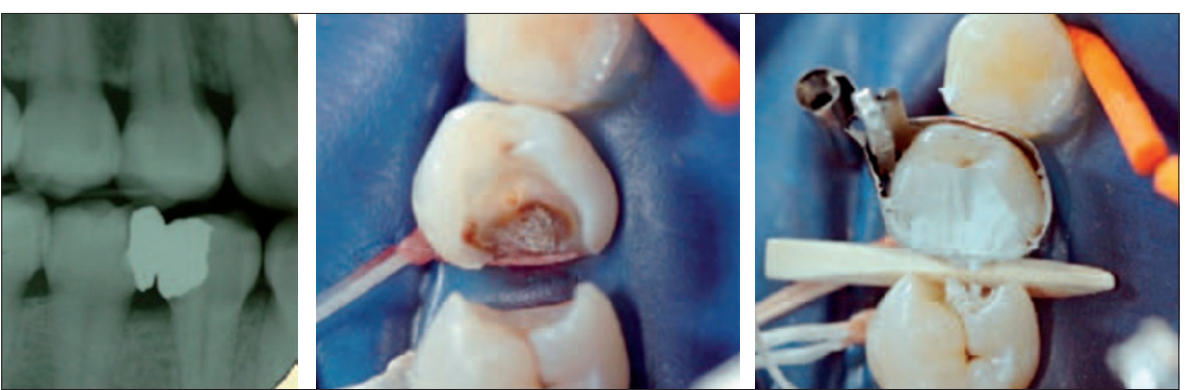

Fig. 8 Biodentine ${ }^{\mathrm{TM}}$ being used as a direct pulp cap. Courtesy of Professor Koubi, Marseille (2009)

trauma to healthy pulp

- Repair of perforated root canals and/or pulp chamber

- Retrograde endodontic surgery

- Pulpotomy in primary molars

- Apexification.

Ten patients per endodontic procedure have been included in the study and will be followed up at three months and two years postoperatively. No interim results have yet been released.

\section{CONCLUSION}

This new calcium-based cement with its purported biocompatible and bioactive properties aims to regenerate damaged dental tissues and represents a promising evolution of the MTA technology. Its clinical advantage lies in its enhanced mechanical properties, its ability to form a good marginal seal and reduced setting time, which can allow for its additional usage as a temporary bulk dentine substitute. Furthermore, with minimal requirement for cavity preparation, no need for photoactivation and good handling properties, this material is user-friendly and clinically practical. The evidence-based research for this material's properties is, however, limited at present. Currently, experimental in vitro, in vivo and ex vivo results have so far substantiated the manufacturers claims that the material is bioactive and biocompatible. However, the number of studies are small and half have used animal models, which offer an imperfect comparison to human dentino-pulpal responses. The clinical in vivo trials are still ongoing and further trials will be needed to determine whether the in vitro results will translate into clinical practice. Importantly, independent case reports, clinical trials and randomised control trials are lacking and are necessary if this material is to become a permanent fixture within the clinician's armamentarium.
The authors would like to state that there is no affiliation between themselves and with the manufacturer (Septodont, Saint Maur Des Fossés, France) of this product.

1. Emerging trends in (bio)material research; Repair or regeneration, a short review. In Goldberg M (ed) Biocompatibility or cytotoxic effects of dental composites. Chapter VI-1. Working group of ORE-FDI. Oxfordshire: Coxmoor Publishing Co, 2009.

2. Laurent $P$, Aubut $V$, About I. Biological properties; Development of a bioactive $\mathrm{Ca}_{3} \mathrm{SiO}$ based posterior restorative material (Biodentine ${ }^{\mathrm{TM}}$ ). In Goldberg M (ed) Biocompatibility or cytotoxic effects of dental composites. Chapter VI-2-2-1. Working group of ORE-FDI. Oxfordshire: Coxmoor Publishing Co, 2009.

3. Torabinejad M, Hong C U, Mc Donald F, Pitt Ford T R. Physical and chemical properties of a new rootend filling material. J Endod 1995; 21: 349-353

4. Camilleri J, Montessin F E, Brady K, Sweeney R Curtis R V, Pitt Ford T R. The constitution of mineral trioxide aggregate. Dent Mater 2005; 21: 297-303

5. Pitt Ford T R, Torabinejad M, Abedi H. Using MTA as a pulp capping material. J Am Dent Assoc 1996; 127: 1491-1494

6. Research and development department Septodont, Biodentine $^{\mathrm{TM}}$; Active Biosilicate Technology ${ }^{\mathrm{TM}}$. Internal data; scientific file, 2009

7. Laurent $P$, Camps J, De Méo M, Déjou J, About I. Induction of specific cell responses to a $\mathrm{Ca}_{3} \mathrm{SiO}_{5}$ based posterior restorative material. Dent Mater 2008; 24: 1486-1494

8. Koubi G, Franquin J C, Colon P. A clinical study of a new $\mathrm{Ca}_{3} \mathrm{SiO}_{5}$-based material indicated as a dentine substitute. Abstract in Clin Oral Invest 2009 and poster Consuero 2009 Seville, Spain March 12th14th 2009.

9. Pradelle-Plasse N, Tran X V, Colon P. Physicochemical properties. In Goldberg M (ed) Biocompatibility or cytotoxic effects of dental composites. Chapter VI-2-1. Working group of ORE-FDI. Oxfordshire: Coxmoor Publishing Co, 2009.

10. Dental materials and their selection. O'Brien W (ed). 4th ed. Ed Quintessence Publishing Company, 2008.

11. Santos A D, Moraes J C, Araujo E B, Yukimitu K, Valerio Filho W V. Physico-chemical properties of MTA and a novel experimental cement. Int Endod J 2005; 38: 443-447

12. Déjou J, Raskin A, Colombani J, About I. Physical, chemical and mechanical behaviour of a new material for direct posterior fillings. Eur Cell Mater 2005; 10: 22

13. Tran V, Pradelle N, Colon P. Microleakage of a new restorative calcium based cement (Biodentine ${ }^{\circledR}$ ). Oral Presentation PEF IADR 2008.

14. Koubi S, Elmerini H, Koubi G, Tassery H, Camps J. Quantitative evaluation by glucose diffusion of microleakage in aged calcium silicate based open sandwich restorations. Int J Dent 2012; DOI: 10.1155/2012/105863.

15. Boinon C, Bottero-Cornillac M J, Koubi G, Déjou Evaluation of adhesion between composite resins and an experimental mineral restorative material. Euro Cell Mater 2007; 13: 17.

16. Quote from Professor T Watson. The French Revolution. The Dentist 2010; 26: 73-72.

17. Boukpessi T, Septier D, Goldberg M. Animal Studies. In Goldberg M (ed) Biocompatibility or cytotoxic effects of dental composites. Working group of 
ORE-FDI. Oxfordshire: Coxmoor Publishing Co, 2009.

18. Laurent $\mathrm{P}$, Camps J, About I. Biodentine $\mathrm{T}^{\mathrm{TM}}$ induces TGF- $\beta 1$ release from human pulp cells and early dental pulp mineralisation. Int Endod J 2011 DOI: 10/1111/j.1365-2591.2011.01995.x.

19. Han L, Okiji T. Uptake of calcium and silicon released from calcium silicate based endodontic materials into root canal dentine. Int Endod J 2011; DOI: 10.1111/j.1365-2591.2011.01924.x

20. About I, Raskin A, De Meo M, Déjou J. Cytotoxicity and Genotoxicity of a new material for direct posterior fillings. Euro Cell Mater 2005; 10: 23
21. Biodentine ${ }^{T M} ;$ Active Biosilicate Technology ${ }^{T M}$ Product Information Leaflet 2009. Septodont, Saint Maur Des Fossés, France.

22. Shayegan A. Etude n ${ }^{\circ} \mathrm{PC} 08-001$. Etude de RD94 comme agen pulpaire dans le cadre de pulpotomie et coiffage direct sur les dents lactéales de cochon. Report RD RA DEV 94-006.

23. Han L, Okiji T. Uptake of calcium and silicon released from calcium silicate-based endodontic materials into root canal dentine. Int Endod J 2011; 44: 1081-1087.

24. About I, Raskin A, De Meo M, Déjou J. Cytotoxicity and genotoxicity of a new material for direct restorative posterior fillings. Eur Cell Mater 2005; 10: 23

25. Machtou P. Open trial, not randomised study evaluating the efficacy and the tolerance of RD94 in patients needing endodontic care, medical device class III. 2009a 09/001.

26. About I, Bottero M J, de Denato P, Camps J, Franquin J C, Mitsiadis T A. Human dentin production in vitro. Exp Cell Res 2000; 258: 33-41.

27. Boukpessi T, Décup F, Septier D, Chaussain-Miller C, Goldberg M. RD94 In indirect pulp-capping situation induces reactionary dentin formation. IADR-CED congress in Munich, Germany, 2009. 